\title{
ANALISIS KESESUAIAN KUALITAS PERAIRAN LAHAN TAMBAK UNTUK BUDIDAYA RUMPUT LAUT (Gracilaria sp.) DI KECAMATAN LANGSA BARAT, KOTA LANGSA
}

\author{
A.B. Susanto ${ }^{\mathrm{a}}$, Rinawati Siregar ${ }^{\mathrm{b}}$ Hanisah $^{\mathrm{c}}$, Teuku Muhammad Faisal ${ }^{\mathrm{b}^{*}}$, Antonid

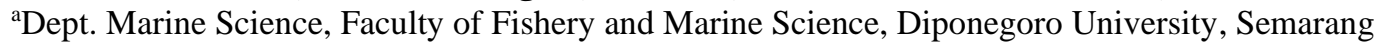 \\ ${ }^{b}$ Dept. Aquaculture, Faculty Agriculture, Samudra University, Langsa \\ ${ }^{c}$ Dept. Agribusiness, Faculty Agriculture, Samudra University, Langsa \\ ${ }^{\mathrm{d} D e p t . ~ A q u a t i c ~ R e s o u r c e s ~ M a n a g e m e n t, ~ F a c u l t y ~ o f ~ F i s h e r i e s ~ a n d ~ M a r i n e ~ S c i e n c e, ~ I P B ~ U n i v e r s i t y, ~ B o g o r ~}$ \\ *Korespondesi Penulis: teukumuhammadfaisal@gmail.com
}

\begin{abstract}
Abstrak
Rumput laut (Gracilaria sp.) merupakan salah satu hasil perairan yang memiliki peluang cukup besar di bidang budidaya. Kualitas perairan di lahan tambak yang sesuai untuk tempat budidaya akan menunjang hasil produksi rumput laut meningkat. Tujuan dari penelitian ini ingin mengkaji kesesuaian kualitas perairan lahan berupa tambak budidaya di Kecamatan Langsa Barat, Kota Langsa, Aceh. Metode yang digunakan adalah survey di lapangan dengan melihat karakteristik dan tingkat kelayakan lahan tambak budidaya rumput laut berdasarkan parameter fisika (suhu, kecerahan, kedalaman, , substrat, arus dan pasang surut) dan parameter kimia (salinitas, $\mathrm{pH}$, oksigen terlarut, fosfat dan nitrat). Pengambilan sampel sebanyak 5 stasiun dengan 3 titik ditentukan dengan pengambilan sampel di bagian inlet, middle, dan outlet tambak. Data hasil penelitian dianalisis dengan menggunakan metode pembobotan. Setelah diperoleh nilai skor dari setiap parameter pada setiap titik pengamatan, kemudian dilakukan penghitungan menggunakan program Microsoft Excel untuk menentukan penilaian sesuai (S1) dengan kisaran nilai 68-87, cukup sesuai (S2) dengan kisaran nilai 48-67 dan tidak sesuai (N) dengan kisaran nilai 28-47. Dari hasil analisis data diperoleh hasil bahwa stasiun I, II, dan IV dalam kategori sesuai (S1), sedangkan stasiun III dan V dalam kategori cukup sesuai.
\end{abstract}

Kata kunci: budidaya, kesesuaian lahan, kualitas air, rumput laut

\begin{abstract}
Seaweed (Gracilaria sp.) is one of the aquatic products that have considerable opportunities in the field of cultivation. Water quality in ponds suitable for cultivation will support increased seaweed production. The purpose of this study is to examine the suitability of the quality of land waters in the form of aquaculture ponds in West Langsa District, Langsa City, Aceh. The method used is a field survey by looking at the characteristics and feasibility of seaweed farming ponds based on physical parameters (temperature, brightness, depth, substrate, currents, and tides) and chemical parameters (salinity, $\mathrm{pH}$, dissolved oxygen, phosphate, and nitrate). A sampling of 5 stations with 3 points is determined by sampling at the inlet, middle, and outlet of the pond. The research data were analyzed using the weighting method. After obtaining the score value of each parameter at each observation point, then calculations are carried out using the Microsoft Excel program to determine the appropriate assessment (S1) with a value range of $68-87$, quite appropriate (S2) with a value range of 48-67 and not appropriate (N) with a value range of 2847. Results of data analysis, it was found that stations I, II, and IV were in the appropriate category (S1), while stations III and V were in the appropriate category.
\end{abstract}

Keywords: aquaculture, land suitability, seaweed

\section{PENDAHULUAN}

Indonesia merupakan negara kepulauan dengan sumberdaya perikanan dan kelautan yang dapat dikembangkan untuk meningkatkan perekonomian nasional, salah satunya adalah pengembangan perikanan pada 
komoditas rumput laut. Pada saat ini kegiatan pengembangannya telah dilakukan di seluruh perairan Indonesia, beradasarkan data dari luas lahan yang dapat dimanfaatkan untuk budidaya rumput laut mencapai $769.452 \mathrm{Ha}$ [1]. Dari jumlah tersebut, sekitar 50\% atau seluas 384.733 Ha yang secara efektif dimanfaatkan, dan akan terus dimanfaatkan sehingga target produksi tahun 2020 sebesar 10 juta ton dapat dicapai [2].

Rumput laut dari kelas Rhodophyceae yang ini termasuk kelompok penghasil agaragar merupakan komoditas ekspor sangat penting dari produk kelautan dan perikanan. Produksi rumput laut selama lima tahun terakhir mengalami trend positif. Produksi rumput laut nasional tahun 2013 mencapai 9,2 juta ton, kemudian pada tahun 2014 tercatat sebesar 10,8 juta ton [3]. Rumput laut (Gracilaria sp.) merupakan spesies rumput laut yang memiliki toleransi yang besar terhadap perubahan kondisi lingkungan sekitarnya sehingga lebih mudah untuk dibudidayakan [4]. Rumput laut (Gracilaria sp.) adalah tipe spesies euryhalin, memiliki toleransi yang besar terhadap perubahan salinitas dari 10 hingga 40 ppt dengan salinitas optimum 25-33 ppt. Rumput laut (Gracilaria sp.) juga bisa bertahan pada perairan dengan $\mathrm{pH}$ 6-9 dengan suhu optimal 20-28 ${ }^{\circ} \mathrm{C}[5]$.

Pengembangan usaha budidaya rumput laut mempunyai prospek yang sangat baik jika dilihat dari potensi sumberdaya lahan yang sangat besar, kemudian jika ditunjang dari beberapa karakteristik lain yaitu dengan teknologi yang digunakan untuk budidaya rumput laut cukup sederhana, tidak diperlukan modal yang besar untuk memproduksi rumput laut melalui bidang budidaya, mengingat terutama permintaan rumput laut yang sangat besar [6].

Kecamatan Langsa Barat merupakan salah satu kecamatan di Kota Langsa, yang memiliki luas wilayah $4.878 \mathrm{Ha}$ atau 48,78

$\mathrm{Km}^{2}$. Secara geografis Kecamatan Langsa Barat terletak pada posisi $4.470750^{\circ}-4.5020^{\circ}$ Lintang Utara dan $97.9605^{\circ}-97.9773^{\circ}$ Lintang Timur. Secara administratif Kecamatan Langsa Barat, sebelah utara yang berbatasan dengan selat malaka [7].
Kecamatan Langsa Barat merupakan daerah yang sebagian besar wilayahnya adalah pemukiman penduduk dan area perikanan budidaya air payau. Sebagian besar lokasinya yang berbatasan dengan laut merupakan lokasi ideal untuk dijadikan lahan budidaya perikanan/tambak. Komoditas utama yang dihasilkan dari tambak budidaya di daerah ini antara lain udang, kepiting, bandeng dan kerapu. Seiring dengan usaha untuk pengembangan budidaya rumput laut (Gracilaria sp.) di Kecamatan Langsa Barat, maka diperlukan pemetaan lahan tambak berdasarkan syarat kesesuaian lahan tambak yang sesuai untuk dijadikan budidaya rumput laut. Pemetaan lahan tambak dan melihat kesesuaian lahan yang baik untuk budidaya rumput laut diharapkan dapat menjadi salah satu strategi pengembangan tambak yang baik untuk budidaya rumput laut (Gracilaria sp.) di kecamatan Langsa Barat.

Saat ini di Kecamatan Langsa Barat belum pernah dilakukan budidaya rumput laut (Gracilaria sp.), kemungkinan besar tidak dimanfaatkannya lahan tambak untuk melakukan pengembangan budidaya rumput laut di daerah ini karena adanya alih fungsi lahan untuk pemukiman warga, kondisi perairan, dan kesesuaian lahan yang belum diketahui. Maka dari itu dilakukan penelitian tentang analisis kesesuaian kualitas perairan di lahan tambak agar dapat diketahui lahan yang sesuai untuk dijadikan budidaya rumput laut. Selain itu menjadi prospek untuk menambah penghasilan bagi masyarakat yang membudidaya rumput laut (Gracilaria sp.).

Tujuan dari penelitian ini adalah untuk mengetahui dan mengkaji kesesuaian lahan tambak untuk dijadikan budidaya Rumput laut (Gracilaria sp.) di Kecamatan Langsa Barat, serta melihat daya dukung lahan yang dapat mengembangkan budidaya Rumput laut di tambak Kecamatan Langsa Barat.

\section{METODE}

\section{Waktu dan Lokasi Penelitian}

Penelitian ini dilaksanakan mulai dari bulan Maret - April 2019 di kawasan tambak Kecamatan Langsa Barat, Kota Langsa meliputi studi literatur, pengambilan titik 
(tagging), pengambilan data lapangan, analisis data berupa kualitas air (fosfat) di Laboratorium Balai Teknik Kesehatan Lingkungan dan Pengendalian Penyakit (BTKLPP) Kelas I Medan dan analisis substrat di Laboratorium Teknik Sipil, Fakultas Teknik, Universitas Samudra.

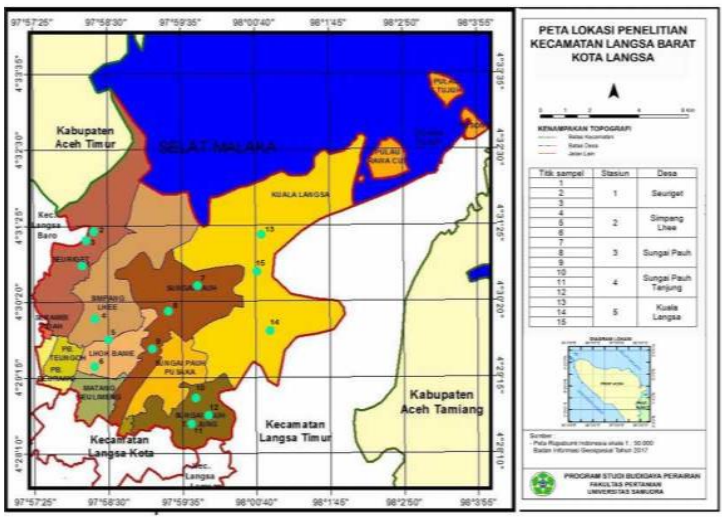

Gambar 1. Peta lokasi penelitian

\section{Tahapan Penelitian}

Penelitian ini dilakukan dalam beberapa tahap, diantaranya sebagai berikut: (1) Persiapan alat untuk survei lapang, alat yang digunakan untuk survei lapangan yaitu hand GPSmap, kamera digital. (2) Persiapan alat untuk mengukur kesesuaian lahan, alat yang digunakan untuk mengukur kesesuaian lahan tambak budidaya rumput laut yaitu $\mathrm{pH}$ meter, DO meter, refraktometer, secchi disc, current meter. (3) Persiapan bahan untuk lokasi penelitian, bahan yang digunakan yaitu Peta Rupa Bumi Indonesia (RBI) yang diperoleh dari pengolahan perangkat lunak SIG dengan aplikasi Arcview.

\section{Pembuatan Peta}

Dasar Penelitian dilakukan dengan melakukan pembuatan peta penggunaan lahan dan pengumpulan data lapang. Peta RBI digunakan sebagai peta dasar dalam pembuatan peta penggunaaan lahan. Tahapan dalam pembuatan peta penutupan lahan mulamula dilakukan koreksi geometrik untuk menyesuaikan koordinat pada peta RBI dengan koordinat geografi. Kemudian dilakukan digitasi untuk menentukan jenis tutupan lahan berdasarkan legenda peta RBI.

\section{Pengumpulan Data}

Pengumpulan data lapang dilakukan dengan mengukur kualitas perairan tambak. Data lapangan yang diambil berjumlah 5 stasiun yang mana setiap stasiun diambil sebanyak 3 titik dengan pengambilan kualitas air pada pagi hari Pukul 07:30 WIB dan sore hari pukul 17:00 WIB. Parameter yang diambil berupa kecerahan, kedalaman, jenis substrat, suhu, salinitas, $\mathrm{pH}$, oksigen terlarut (DO), nitrat dan fosfat. Setiap pengambilan data lapang dilakukan marking menggunakan GPS. Kecerahan diukur menggunakan secchi disc, kedalaman tambak diukur menggunakan paralon berskala, jenis substrat dasar didapatkan dengan menganalisis sampel substrat tambak, oksigen terlarut diukur menggunakan DO meter, suhu diukur menggunakan thermometer, salinitas diukur menggunakan refraktometer, $\mathrm{pH}$ diukur menggunakan $\mathrm{pH}$ Meter, nitrat dan fosfat diukur menggunakan spektrofotometer, Arus diukur dengan current meter.

Tabel 1. Jenis data yang dikumpulkan

\begin{tabular}{clcc}
\hline No & \multicolumn{1}{c}{ Jenis Data } & Satuan & Tempat \\
\hline 1 & Suhu air tambak & ${ }^{\circ} \mathrm{C}$ & In situ \\
2 & Salinitas & $\mathrm{ppt}$ & In situ \\
3 & Kedalaman tambak & $\mathrm{cm}$ & In situ \\
4 & Kecerahan tambak & $\%$ & In situ \\
5 & Substrat & - & Lab \\
6 & Derajat keasaman $(\mathrm{pH})$ & - & In situ \\
7 & Fosfat & $\mathrm{ppm}$ & Lab \\
8 & Oksigen terlarut $(\mathrm{DO}$ & $\mathrm{ppm}$ & In situ \\
9 & Nitrat & $\mathrm{ppm}$ & In situ \\
10 & Pasang surut & $\mathrm{cm}$ & In situ \\
\hline
\end{tabular}

Keterangan: lab $=$ laboratorium

\section{Analisis Data}

Tahapan Analisis Data

Tahap pertama, penetapan angka penilaian berdasarkan petunjuk DKP (Dinas Kelautan dan Perikanan) [8], yaitu 3= baik; 2= sedang dan $1=$ kurang.

Tahap kedua, persyaratan berupa parameter dan kriteria yang masing-masing memiliki nilai bobot. Pembobotan dilakukan dengan mengacu tingkat parameter yang sangat menentukan. Parameter yang sesuai diberi bobot 3, parameter yang cukup sesuai diberi bobot 2 dan parameter yang tidak sesuai diberi bobot 1 . 
Tahap ketiga, nilai skor diperoleh dengan menggunakan persamaan Utoyo et al [9] sebagai berikut: nilai skor $=\Sigma$ Skor $\mathrm{x}$ Bobot.

Tahap keempat, data yang diperoleh dilapangan, diolah dan dianalisis untuk menentukan kelayakan lahan tambak rumput laut (Gracilaria sp.), menggunakan kriteria yang terdapat di Tabel 1.

Tahap kelima, setelah mengetahui nilai skor untuk setiap parameter pada setiap stasiun maka dilakukan dengan penilaian hasil evaluasi dengan menggunakan Tabel 2 untuk menentukan apakah lokasi tersebut sesuai (S1), cukup sesuai (S2) dan tidak sesuai $(\mathrm{N})$ untuk tambak budidaya rumput laut (Gracilaria sp.). Penilaian skor hasil evaluasi diperoleh dengan persamaan yang dikemukakan oleh Nurdin et al adalah sebagai berikut:

$$
C i=\frac{\text { Bobot } \max -\text { Bobot } \min }{n}
$$

Keterangan:

$\mathrm{Ci}=$ range antar kelas

$\mathrm{n}=$ jumlah kelas yang direncanakan

Bobot maksimal adalah 3, bobot minimal adalah 1. jadi $3+3+3+2+3+2+3+3+2+3+2=$ 29. 29 merupakan jumlah bobot dari setiap variabel. Maka hasilnya adalah bobot maksimal $=29 \times 3=87$, sedangkan bobot minimal $29 \times 1=29$.

Range antar kelas $(\mathrm{Ci})$ ditentukan dengan persamaan berikut ini: $\mathrm{n}=3(\mathrm{~S} 1, \mathrm{~S} 2, \mathrm{~N})$

$$
C i=\frac{87-29}{3}=19
$$

Maka, nilai interval dari setiap kelas adalah 19:

$\begin{array}{ll}\text { Sesuai (S1) } & =68-87 \\ \text { Cukup Sesuai (S2) } & =48-67 \\ \text { Tidak Sesuai }(\mathrm{N}) & =28-47\end{array}$

Tahap keenam, melakukan pemetaan berdasarkan hasil dari penentuan kelas kelayakan tambak yang telah di analisis terhadap tingkat kelayakan tambak. Pembuatan peta dengan menggunakan software Arcgis program Arcmap.

\begin{tabular}{|c|c|c|c|}
\hline No & $\begin{array}{c}\text { Kisaran } \\
\text { Nilai }\end{array}$ & Kelas & $\begin{array}{c}\text { Penilaia hasil } \\
\text { evaluasi }\end{array}$ \\
\hline 1 & $68-87$ & $\begin{array}{l}\text { Sesuai } \\
\text { (S1) }\end{array}$ & $\begin{array}{l}\text { Daerah ini tidak } \\
\text { mempunyai } \\
\text { pembatas } \\
\text { (penghambat) } \\
\text { yang berarti. }\end{array}$ \\
\hline 2 & $48-67$ & $\begin{array}{l}\text { Cukup sesuai } \\
\text { (S2) }\end{array}$ & $\begin{array}{l}\text { Daerah ini } \\
\text { mempunyai } \\
\text { pembatas } \\
\text { (penghambat) } \\
\text { yang cukup } \\
\text { berarti. }\end{array}$ \\
\hline 3 & $28-47$ & $\begin{array}{c}\text { Tidak sesuai } \\
\text { (N) }\end{array}$ & $\begin{array}{l}\text { Daerah ini } \\
\text { mempunyai } \\
\text { pembatas } \\
\text { (penghambat) } \\
\text { dengan tingkat } \\
\text { sangat berat. }\end{array}$ \\
\hline
\end{tabular}

Tabel 2. Sistem penilaian hasil kelayakan

\section{HASIL DAN PEMBAHASAN}

\section{Lokasi pengambilan sampel}

Penelitian kesesuaian tambak untuk budidaya rumput laut (Gracilaria sp.) ini dilaksanakan di tujuh desa yang terdapat di Kecamatan Langsa Barat yaitu Desa Seuriget dengan luas wilayah 728 ha, Desa Simpang Lhee dengan luas 661 ha, Desa Lhok Banie dengan luas 187 ha, Desa Sungai Pauh dengan luas 631 ha, Sungai Pauh Tanjong dengan luas 315 ha, Desa Sungai Pauh Pusaka dengan luas 249 ha dan Desa Kuala Langsa dengan luas 1.545 ha. Pemilihan lokasi ini dilakukan karena lokasi ini merupakan daerah yang terdapat tambak untuk budidaya.

Stasiun pengamatan I berada di Desa Seuriget Kecamatan Langsa Barat. Titik I terletak pada koordinat $97^{\circ} 57^{\prime} 25^{\prime \prime} \mathrm{E}$ dan

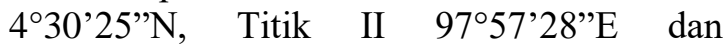
4'30'31'N serta Titik III 97'57'30'E dan $4^{\circ} 30^{\prime} 25^{\prime} \mathrm{N}$. Tambak ini terletak dekat dengan pemukiman warga dan di sekitar tambak ini berupa pohon mangrove. Stasiun pengamatan II berada di Desa Simpang Lhee dan Lhok Banie. Titik I terletak pada Koordinat $97^{\circ} 58^{\prime} 30^{\prime \prime} \mathrm{N}$ dan $4^{\circ} 29^{\prime} 15^{\prime} \mathrm{E}$, titik II $97^{\circ} 58^{\prime} 30^{\prime \prime} \mathrm{N}$ dan $4^{\circ} 29^{\prime} 15^{\prime \prime} \mathrm{E}$ serta titik III 
97'58'30”N dan 4²9'20'”. Tambak ini terletak jauh dari pantai tetapi dekat dengan pemukiman warga. Stasiun pengamatan III berada di Desa Sungai Pauh dengan Titik I terletak pada koordinat 97'59'35" $\mathrm{N}$ dan $4^{\circ} 29^{\prime} 15^{\prime \prime} \mathrm{E}, \quad$ titik II $97^{\circ} 59^{\prime} 35^{\prime \prime} \mathrm{N}$ dan $4^{\circ} 29^{\prime} 15^{\prime \prime}$ 'E serta titik III $97^{\circ} 58^{\prime} 30^{\prime \prime} \mathrm{N}$ dan $4^{\circ} 30^{\prime} 20^{\prime \prime}$. Tambak ini lumayan dekat dengan pantai dan dekat dengan jalan umum dan pemukiman warga. Stasiun pengamatan IV berada di Desa Sungai Pauh Tanjong dengan titik I terletak pada koordinat $97^{\circ} 59^{\prime} 35^{\prime \prime} \mathrm{N}$ dan $4^{\circ} 28^{\prime} 10^{\prime \prime} \mathrm{E}, \quad$ titik II $97^{\circ} 59^{\prime} 35^{\prime} \mathrm{N}$ dan $4^{\circ} 28^{\prime} 10^{\prime \prime}$ E serta titik III 97'59'35'N dan $4^{\circ} 28^{\prime} 10^{\prime \prime}$.E. Tambak ini berada jauh dengan pantai tetapi dekat dengan pemukiman warga dan di sekitar tambak berupa pohon mangrove. Stasiun pengamatan $\mathrm{V}$ berada di Desa Sungai Pauh Pusaka dan Kuala langsa. Titik I terletak pada koordinat $98^{\circ} 00^{\prime} 40^{\prime \prime} \mathrm{N}$ dan 4'30'20'"E, titik II $98^{\circ} 00^{\prime} 40^{\prime \prime} \mathrm{N}$ dan $4^{\circ} 29^{\prime} 15^{\prime \prime} \mathrm{E}$ serta titik III 97'59'35'N dan 4'29'15'"E. Tambak ini berada di daerah pesisir, dekat dengan jalan umum dan pemukiman warga pesisir.

\section{Parameter-parameter Fisika dan Kimia}

\section{Salinitas}

Salinitas adalah tingkat keasinan atau garam terlarut dalam air. Rumput laut merupakan spesies yang memiliki toleransi yang cukup tinggi namun perubahan salinitas perairan rumput laut yang signifikan dapat menurunkan laju pertumbuhan dan hasil produksi [11]. Salinitas yang didapatkan melalui pengukuran di lokasi penelitian berkisar antara 33-37,4 ppt (gambar 2).

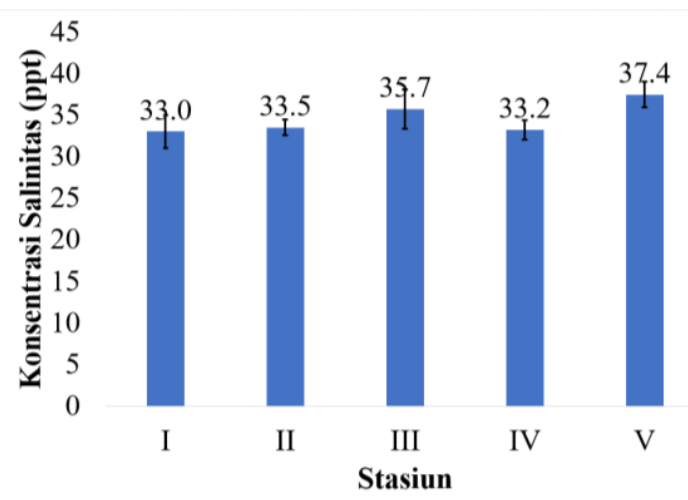

Gambar 2. Kondisi salinitas disetiap stasiun
Berdasarkan hasil pengukuran salinitas di lokasi penelitian menunjukkan perbedaan nilai setiap stasiun. Nilai salinitas tertinggi terdapat pada stasiun V 37,4 ppt sedangkan yang terendah terdapat pada stasiun I yaitu $33 \mathrm{ppt}$. Adanya perbedaan salinitas tambak diduga karena faktor letak dan sumber air tambak [12]. Selain itu perbedaan salinitas disebabkan oleh perbedaan waktu saat pengambilan sampel berpengaruh pada proses penguapan. Dimana stasiun III dan V dekat dengan pantai sehingga campuran air tawarnya sangat sedikit, adapun stasiun I, II dan IV mendapat campuran air tawar.

Kisaran salinitas perairan tambak paling rendah berada pada stasiun I, II dan IV namun masuk pada kondisi cukup sesuai 24-35 ppt sedangkan stasiun III dan V masuk pada kondisi tidak sesuai sehingga tidak cocok untuk budidaya rumput laut (Gracilaria sp.). Terdapat perbedaan salinitas karena pada waktu pengambilan sampel pada pagi dan sore hari dimana pada waktu sore salinitasnya lebih tinggi dibandingkan pada waktu pagi. Hal ini disebabkan tingginya suhu perairan jika semakin tinggi suhu maka salinitas akan meningkat. Hal ini sesuai dengan pendapat yang dikemukakan oleh Trono [13], bahwa salinitas yang sesuai untuk pertumbuhan optimal rumput laut (Gracilaria sp.) adalah 15-24 ppt. Jika salinitas perairan rendah maka rumput laut tidak tumbuh dengan normal dan berwarna pucat. Sebaliknya jika salinitas perairan tinggi akan menyebabkan thallus rumput laut menjadi pucat kekuning-kuningan dan rentan terhadap penyakit.

\section{$p H$}

$\mathrm{pH}$ adalah derajat keasaman suatu perairan. Nilai $\mathrm{pH}$ berpengaruh terhadap pertumbuhan dan pembentukan gel rumput laut dalam pembuatan agar-agar [14]. $\mathrm{pH}$ yang didapatkan melalui pengukuran di lokasi penelitian berkisar antara 7,1-7,5 (gambar 3).

Berdasarkan hasil pengukuran $\mathrm{pH}$ di lokasi penelitian berkisar 7,1-7,5. Lokasi yang memiliki nilai $\mathrm{pH}$ tertinggi terdapat pada stasiun II yaitu 7,5 sedangkan yang terendah adalah pada stasiun I dan V yaitu 7,1. 


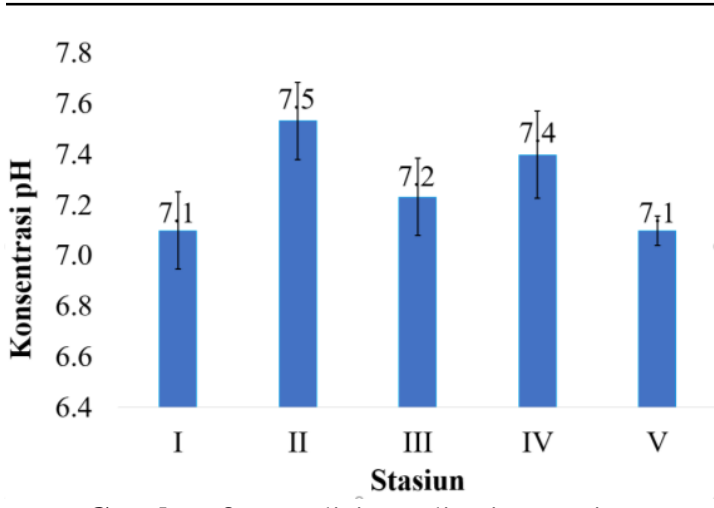

Gambar 3. Kondisi pH disetiap stasiun

Nilai $\mathrm{pH}$ cukup sesuai untuk budidaya rumput laut (Gracilaria sp.) pada semua stasiun. Hal ini dikemukakan oleh Badruddin et al [15], bahwa $\mathrm{pH}$ yang cocok untuk pertumbuhan rumput laut (Gracilaria sp.) umumnya berkisar antara 6,2-8,2. Sedangkan yang optimal adalah 6-8. Kandungan derajat keasaman ini masih dalam kisaran sesuai jika ditinjau dari tingkat kesesuaian lahan perairan untuk budidaya rumput laut (Gracilaria sp.)

\section{Oksigen Terlarut (DO)}

Oksigen terlarut adalah kandungan oksigen yang terlarut dalam perairan yang merupakan suatu komponen utama bagi metabolisme organisme perairan yang digunakan untuk pertumbuhan, reproduksi dan kesuburan alga [16]. Oksigen terlarut di perairan dianggap sebagai parameter yang tersier karena keberadaan parameter ini tidak berhubungan langsung dengan rumput laut. Rumput laut hanya membutuhkan oksigen pada kondisi tanpa cahaya [17]. Oksigen terlarut (DO) yang didapatkan melalui pengukuran di lokasi penelitian berkisar antara 4,6-7,5 (gambar 4).

Dari 5 stasiun pengamatan diperoleh konsentrasi oksigen terlarut rata-rata setiap stasiun dapat dilihat pada gambar 4 yang berkisar antara 4,6-7,5 ppm. Dimana stasiun I memiliki konsentrasi DO yang rendah yaitu 4,6 ppm. Sedangkan stasiun IV memiliki konsentrasi DO yang tinggi yaitu $7,5 \mathrm{ppm}$. Seperti yang dikemukakan oleh Sulistijo [18], bahwa larutan oksigen yang diperlukan untuk pertumbuhan optimal rumput laut adalah lebih dari 4 ppm. Pada stasiun I sampai V masuk dalam kisaran sesuai. Kandungan oksigen terlarut yang dekat dengan sumber air asin (air

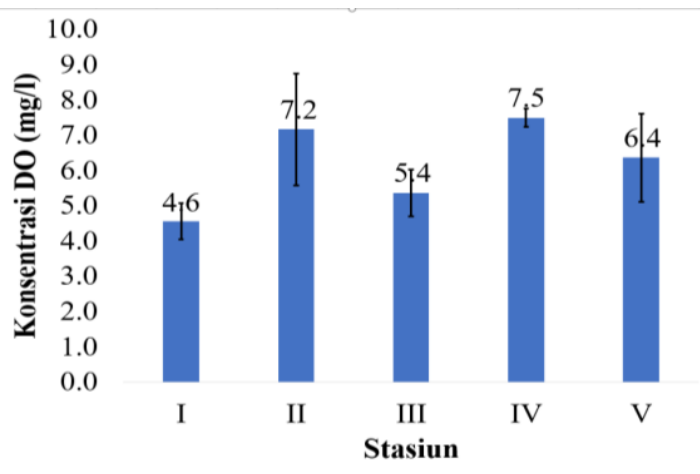

Gambar 4. Kondisi oksigen terlarut (DO) disetiap stasiun

laut) lebih tinggi kandungan oksigen terlarutnya dibandingkan dengan tambak yang jaraknya jauh dengan pasokan air asin (air laut) hal ini dikarenakan pergantian air tambak pada lokasi yang dekat dengan sumber air asin tersebut selalu dilakukan agar kualitas air tambak dalam keadaan yang optimal.

\section{Suhu}

Suhu perairan mempengaruhi laju fotosintesis dan kadar oksigen terlarut. Berdasarkan hasil pengukuran kualitas perairan, suhu yang didapatkan di lokasi penelitian berkisar antara 28 - 33, dapat dilihat pada gambar 5 .

Stasiun I memiliki suhu yang rendah dikarenakan oleh perbedaan waktu pengambilan sampel dan kondisi cuaca pada saat pengukuran. Pada saat pengukuran pagi masih agak mendung dan belum terpapar oleh sinar matahari sedangkan pengukuran pada sore hari kondisi cuaca sudah cerah dan sedikit banyaknya matahari yang masuk ke dalam badan perairan tersebut. Kisaran suhu perairan tambak cukup tinggi menyebabkan rumput laut harus beradaptasi dengan suhu yang tinggi tersebut. Kondisi seperti ini akan berdampak pada pertumbuhan yang lambat dan cenderung mengecil atau kerdil. Suhu dengan kisaran tersebut pada semua stasiun masih cukup sesuai untuk budidaya rumput laut sedangkan untuk suhu yang optimal untuk mendukung pertumbuhan dan perkembangan rumput laut adalah dengan kisaran $22-27^{\circ} \mathrm{C}$, sedangkan suhu maksimal yang dapat ditoleransi oleh rumput laut adalah $32^{\circ} \mathrm{C}$ [19]. 


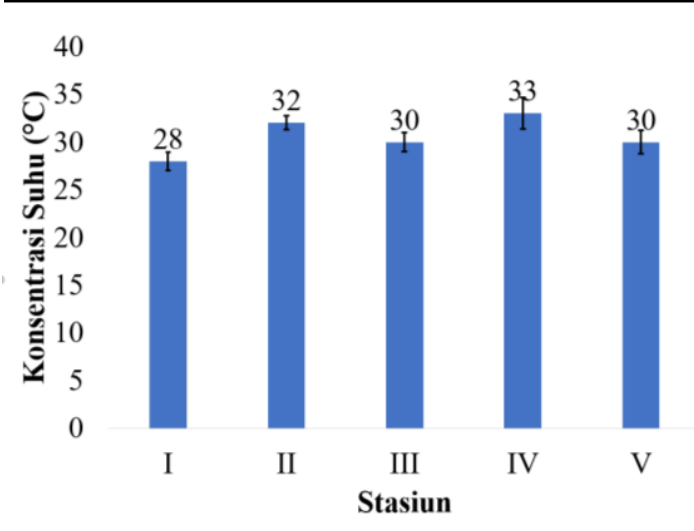

Gambar 5. Kondisi suhu disetiap stasiun

\section{Kecerahan}

Rumput laut merupakan organisme yang dapat mengubah bahan anorganik menjadi organik dengan energi sinar matahari atau disebut dengan fotosintesis. Penetrasi sinar matahari kedalam kolom air sangat bervariasi karena partikel cahaya yang masuk akan diserap dan dibiaskan oleh partikel dan molekul dalam air [4]. Kecerahan yang didapatkan melalui pengukuran di lokasi penelitian berkisar antara $37-58 \mathrm{~cm}$, dapat dilihat pada gambar 6 .

Berdasarkan pengamatan pada gambar diatas terlihat bahwa nilai kecerahan yang tertinggi terdapat pada stasiun II yaitu $58 \mathrm{~cm}$ sedangkan terendah terdapat pada stasiun V yaitu $37 \mathrm{~cm}$. Stasiun I dan stasiun II memiliki kecerahan yang sesuai untuk budidaya rumput laut (Gracilaria sp.). Dimana kecerahan yang paling tinggi terdapat pada stasiun II yaitu 58 $\mathrm{cm}$. Kecerahan yang paling rendah dengan kriteria cukup sesuai terdapat pada stasiun V. Banyak atau sedikitnya sinar matahari yang menembus ke dalam perairan sangat bergantung dari kecerahan air. Semakin cerah perairan tersebut akan semakin dalam cahaya yang menembus ke dalam perairan. Penetrasi cahaya menjadi rendah ketika tingginya kandungan partikel tersuspensi di perairan dekat dengan pantai, akibat aktivitas pasang surut dan juga tingkat kedalaman [20].

Nilai kecerahan yang diperoleh pada semua stasiun cukup sesuai untuk pertumbuhan rumput laut. Kecerahan yang menembus sampai ke dasar tambak mendukung berlangsungnya proses fotosintesis secara maksimal [21]. Nilai kecerahan air yang baik untuk pertumbuhan

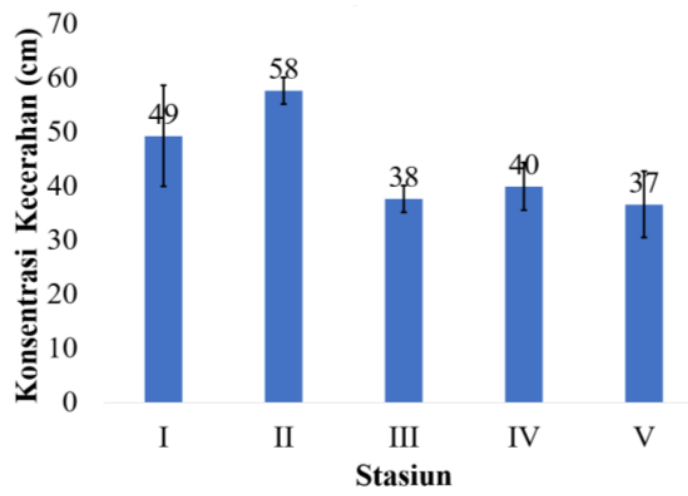

Gambar 6. Kondisi tingkat kecerahan disetiap stasiun

dan kelangsungan organisme perairan adalah lebih besar dari $45 \mathrm{~cm}$. Rendahnya nilai kecerahan perairan umumnya disebabkan oleh tingginya kekeruhan oleh banyaknya bahan organik terlarut dan tersuspensi, benda-benda terapung dan intesitas cahaya [22].

\section{Kedalaman}

Rumput laut memerlukan sinar matahari untuk proses fotosintesis, karena itu rumput laut hanya dapat tumbuh pada perairan dengan kedalaman tertentu dimana sinar matahari dapat sampai ke dasar perairan. Kedalaman rata-rata semua stasiun masih pada taraf yang menguntungkan pertumbuhan dan perkembangan budidaya rumput laut (Gracilaria sp.) karena pada kedalaman tersebut intensitas cahaya matahari sampai pada rumput laut masih sangat tinggi sehingga proses fotosintesis masih dapat berlangsung dengan baik. Budidaya rumput laut di tambak membutuhkan kedalaman $60-80 \mathrm{~cm}$ karena pada kondisi tersebut matahari masih dapat menembus dasar perairan [23]. Kedalaman yang didapatkan melalui pengukuran di lokasi penelitian berkisar antara $56-85 \mathrm{~cm}$, dapat dilihat pada gambar 7 .

Berdasarkan gambar di atas dapat dilihat bahwa kedalaman perairan di lokasi penelitian yang tertinggi terdapat pada stasiun I yaitu 85 $\mathrm{cm}$ dan terendah terdapat pada stasiun $\mathrm{V}$ yaitu $56 \mathrm{~cm}$. Kedalaman perairan pada stasiun II, III, IV dan V masuk dalam kondisi sesuai sedangkan stasiun I masuk dalam kondisi cukup sesuai. Perbedaan kedalaman adalah tinggi rendahnya dasar tambak. Proses pertumbuhan rumput laut sangat bergantung 


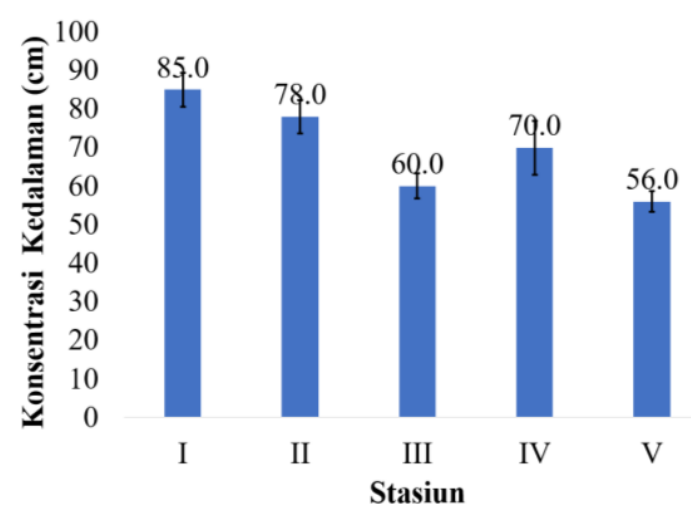

Gambar 7. Kedalaman tambak disetiap stasiun

pada sinar matahari untuk melakukan proses fotosintesis. Jika di suatu daerah akan membatasi penetrasi cahaya matahari maka dengan tidak langsung akan mempengaruhi pertumbuhan rumput laut yang ada didalamnya, karena jumlah oksigen untuk respirasi akan semakin berkurang dengan semakin dalamnya perairan yang disebabkan intensitas cahaya matahari yang masuk kedalam perairan semakin kecil.

Kedalaman perairan yang baik untuk perkembangan rumput laut adalah berkisar antara $50-80 \mathrm{~cm}$. Nilai ini menunjukkan bahwa kedalaman tambak ini tidak boleh kurang dari $50 \mathrm{~cm}$ karena pengaruh suhu di permukaan perairan yang tinggi dapat mempengaruhi pertumbuhan rumput laut tersebut dan tidak lebih dari $80 \mathrm{~cm}$ dengan asumsi bahwa cahaya matahari masih menembus sampai ke dasar perairan [13].

\section{Nitrat}

Unsur hara nitrat merupakan salah satu faktor yang berperan penting dalam mendukung proses metabolisme, pertumbuhan dan kelangsungan hidup organisme. Menurut Trono [13], kadar nitrat yang optimal (layak) untuk dijadikan budidaya rumput laut (Gracilaria sp.) 0,01-0,79 ppm. Kadar nitrat yang didapatkan melalui pengukuran di lokasi penelitian berkisar antara 0,45-0,77 ppm, dapat dilihat pada gambar 8 .

Dari pengamatan diatas dapat dilihat bahwa stasiun dengan kadar nitrat terendah yaitu pada stasiun IV dengan nilai $0,45 \mathrm{ppm}$ dan stasiun tertinggi yaitu pada stasiun III dengan nilai 0,77 . Perbedaaan konsentrasi

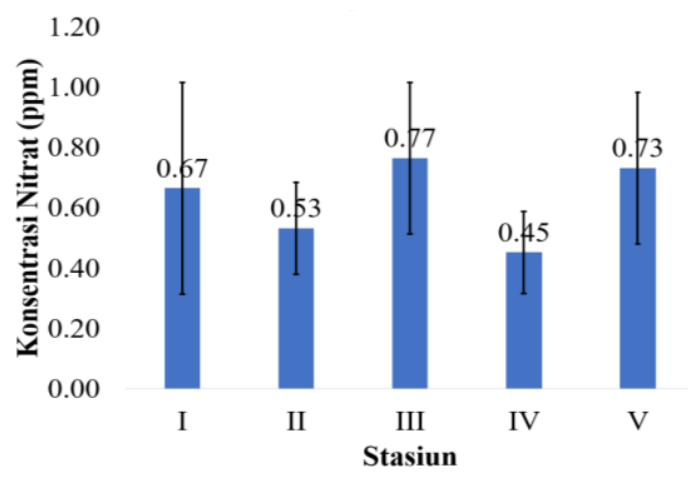

Gambar 8. Kondisi konsentrasi nitrat disetiap stasiun

nitrat dari setiap stasiun disebabkan oleh adanya faktor dari lingkugan, pada saat pengambilan sampel, tambak masih aktif untuk budidaya, indikasinya adalah adanya kotoran-kotoran yang mengendap didasar tambak mengakibatkan meningkatnya nitrat. Menurut Kanglan [24], bahwa kisaran nitrat yang layak untuk organisme 0,2-0,7 ppm. Konsentrasi nitrat diduga mempengaruhi pertumbuhan rumput laut. Jika konsentrasi nitrat di suatu perairan tidak sesuai dengan yang telah ditentukan maka pertumbuhan rumput laut tidak optimal [25].

\section{Fosfat}

Fosfat merupakan bentuk fosfor yang dapat dimanfaatkan oleh tumbuhan. Menurut Mustafa et al [26], bahwa konsentrasi fosfat pada perairan berkisar antara 0.005-0,20 $\mathrm{mg} / \mathrm{L}$, sedangkan pada air tanah biasanya berkisar $0,02 \mathrm{mg} / \mathrm{L}$ selanjutnya dikatakan bahwa PO4 jarang melebihi $1 \mathrm{mg} / \mathrm{L}$, meskipun pada perairan eutrof. Mustafa et al [26], menyatakan bahwa perairan relatif subur jika kisaran zat hara fosfat normal yaitu 0,10-1,68 ppm. Kadar fosfat yang didapatkan melalui pengukuran di lokasi penelitian berkisar antara 0,05-0,14 ppm, dapat dilihat pada gambar 9.

Seluruh stasiun mempunyai kriteria sesuai untuk mendukung pertumbuhan budidaya rumput laut (Gracilaria sp.) terlihat bahwa semua stasiun memiliki nilai fosfat berkisar antara 0,05-0,14 ppm. Hal ini bisa dinyatakan bahwa perairan tergolong bagus untuk pertumbuhan rumput laut. Menurut Trono [13], kadar fosfat yang sesuai yaitu 0,02-1.0 ppm. Tingginya kadar fosfat dapat 


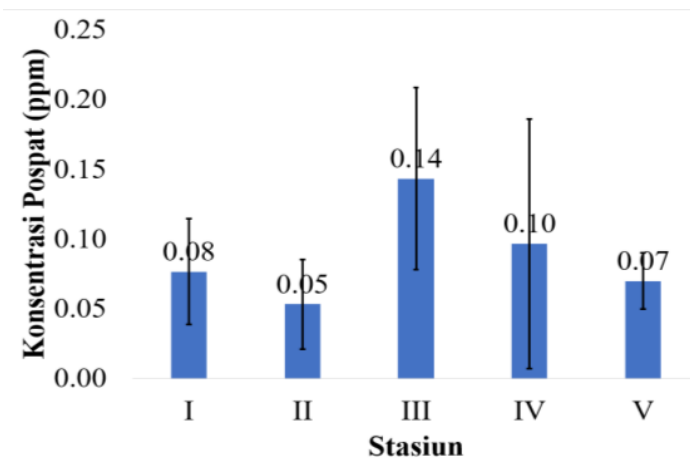

Gambar 9. Kondisi konstrasi fosfat disetiap stasiun

menyebabkan eutrofikasi yang dapat berakibat buruk terhadap perairan karena terlalu banyak fitoplankton sehingga oksigen terlarut pada perairan bisa menurun, sebaliknya jika kadar fosfat rendah maka pertumbuhan rumput laut (Gracilaria sp.) akan terganggu. Senyawa fosfat dalam perairan berasal dari sumber alami seperti erosi tanah, buangan kotoran dari hewan dan pelapukan tumbuhan, dan dari laut itu sendiri. Kondisi yang terdapat pada stasiun III terdapat erosi tanah dan buangan kotoran hewan yang dipelihara oleh masyarakat sekitar, hal inilah yang dapat menyebabkan di stasiun ini memiliki kadar fosfatnya yang lebih tinggi dibandingkan dengan stasiun pengamatan lainnya.

\section{Pasang Surut}

Pada dasarnya kegunaan data pasang surut pada perencanaan lokasi budidaya adalah untuk menentukan lokasi mana yang tepat untuk tambak yang dijadikan sebagai budidaya khususnya untuk pertumbuhan rumput laut (Gracilaria sp.) Pasang surut air juga berfungsi sebagai sirkulasi air dalam tambak sehingga kualitas air dalam tambak tetap terjaga. Kedua fungsi tersebut sangat penting untuk menjaga tambak budidaya agar selalu dalam kondisi yang optimum. Pasang surut yang didapatkan melalui pengukuran di lokasi penelitian, lihat digambar 10.

Berdasarkan hasil pengukuran pada lokasi penelitian, maka dapat diketahui bahwa perairan Kecamatan Langsa Barat sesuai untuk dijadikan sebagai tempat untuk budidaya rumput laut (Gracilaria sp.)

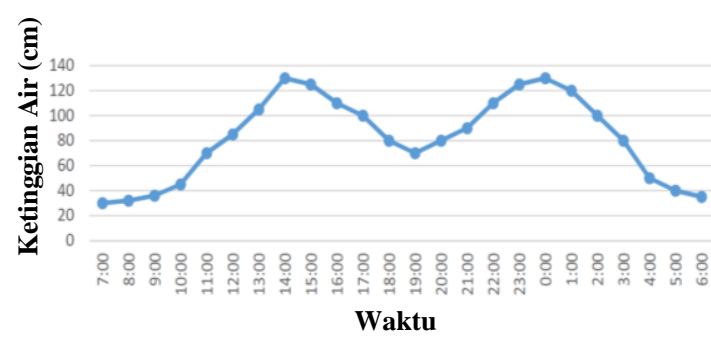

Gambar 10. Grafik pasang surut dipesisir lokasi penelitian

Menurut Sujarwo [27], bahwa pada surut terendah masih digenangi air sekurangkurangnya $30 \mathrm{~cm}$. Hal ini jelas pada pasang surut yang diamati pada semua stasiun masih digenangi air walaupun sedang surut. Pasang surut tertinggi yaitu $130 \mathrm{~cm}$. Sedangkan pasang surut terendah yaitu $30 \mathrm{~cm}$. Untuk mengetahui tipe pasang surut di Kecamatan Langsa Barat maka dapat dilihat pada gambar 10 grafik pasang surut, maka dapat diketahui bahwa tipe pasang surut yang terjadi di perairan kecamatan langsa barat adalah tipe pasang surut harian ganda (semidiurnal tipe), yaitu dalam satu hari terjadi dua kali pasang dan dua kali air surut, dengan tinggi yang hampir sama dan pasang surut terjadi secara teratur.

\section{Substrat}

Substrat dasar dalam suatu perairan adalah salah satu faktor penting didalam membudidayakan rumput laut. Rumput laut pada umumnya hidup menempel pada substrat dasar perairan atau benda lainnya di daerah subtidal dan intertidal [28]. Tipe substrat yang terdapat di tambak Kecamatan Langsa Barat, Kota Langsa dapat dilihat pada tabel 3.

Berdasarkan tabel 3 diatas dapat dilihat bahwa tipe substrat yang terdapat pada tambak Langsa Barat adalah lumpur berpasir dan pasir berkerikil. Substrat dasar yang baik adalah substrat lumpur berpasir. Hal ini

Tabel 3. Hasil analisis substrat

\begin{tabular}{|c|c|}
\hline Stasiun & Tipe Substrat \\
\hline I & Lumpur berpasir \\
\hline II & Lumpur berpasir \\
\hline III & Pasir berkerikil \\
\hline IV & Lumpur berpasir \\
\hline V & Pasir berkerikil \\
\hline \multicolumn{2}{|c|}{$\begin{array}{c}\text { Sumber: Hasil Analisis Substrat di Laboratorium Teknik } \\
\text { Sipil Fakultas Teknik Universitas Samudra. }\end{array}$}
\end{tabular}
Sipil Fakultas Teknik Universitas Samudra. 
adalah salah satu faktor penting dalam membudidayakan rumput laut. Trono [13], mengemukakan bahwa jenis substrat yang terlalu lembut dan terlalu kasar dapat menyebabkan sebagian dari (Gracilaria sp.) tenggelam dan mati. Substrat yang sesuai untuk dijadikan budidaya rumput laut terdapat pada stasiun I, II dan IV. Sedangkan stasiun III dan V masuk dalam kategori tidak sesuai. Berdasarkan pengamatan di lapangan adanya perbedaan substrat pada setiap stasiun adalah dimana stasiun III dan V berada dekat dengan jalan umum dan pemukiman warga sehingga menyebabkan adanya aktivitas dari manusia.

\section{Evaluasi Kesesuaian Kualitas Perairan} Tambak Untuk Budidaya Rumput Laut (Gracilaria sp.)

Nilai pengukuran selanjutnya diberi bobot dan dilakukan skoring. Nilai skoring diperoleh dengan menggunakan persamaan Utojo et al [29] sebagai berikut: Nilai skor $=$ Skor $x$ Bobot Dengan mengacu pada nilai pembobotan dan skor yang telah ditetapkan sebelumnya. Kemudian hasil perhitungan dibandingkan dengan kisaran nilai kelayakan lahan yang telah ditentukan. Apakah lokasi tersebut sesuai, cukup sesuai atau tidak sesuai untuk dijadikan budidaya rumput laut. Hasil perhitungan dan pembagian kelas kelayakan pada setiap titik sampel atau stasiun pengamatan di Kecamatan Langsa Barat disajikan pada tabel 4. Hasil yang dapat dilihat bahwa lahan tambak yang menjadi lokasi untuk penelitian di Kecamatan Langsa Barat di stasiun pengamatan I, II dan IV masuk dalam kategori kelas sesuai, sedangkan stasiun pengamatan III dan V masuk dalam kategori cukup sesuai untuk dijadikan budidaya rumput laut (Gracilaria sp.) karena salah satu yang harus ada dalam budidaya rumput laut adalah tambak yang tidak memiliki arus tinggi dan tergenang air. Parameter yang menjadi pembatas pada stasiun III dan V adalah salinitas dan substrat.

Jika dikaitkan dengan parameter-parameter fisika dan kimia perairan disetiap stasiun yang sudah dilakukan pengambilan data, hasil yang sesuai untuk dijadikan lahan untuk pengembangan budidaya rumput laut di daerah Kecamatan Langsa Barat secara menyeluruh dapat dilihat pada gambar 11 . Jika diamati lebih lanjut hanya 2 area stasiun yang cukup memenuhi kriteria, hal ini diakibatkan oleh faktor dari keadaan atau kondisi perairan dan lahan tambak yang berada di wilayah tersebut. Kondisi perairan tambak pada kedua stasiun tersebut berdasarkan parameter-parameter kualitas perairan (fisika dan kimia) pada setiap stasiun yang telah diamati dan telah dianalisis berdasarkan kriteria yang telah ditentukan.

Tabel 4. Penentuan kelayakan untuk budidaya rumput laut (Gracilaria sp.) di setiap stasiun

\begin{tabular}{|c|c|c|c|c|c|c|c|c|c|c|c|c|}
\hline \multirow{2}{*}{ No } & \multirow{2}{*}{ Parameter } & \multirow{2}{*}{ Bobot } & \multicolumn{2}{|c|}{ Stasiun 1} & \multicolumn{2}{|c|}{ Stasiun 2} & \multicolumn{2}{|c|}{ Stasiun 3} & \multicolumn{2}{|c|}{ Stasiun 4} & \multicolumn{2}{|c|}{ Stasiun 5} \\
\hline & & & Skor & NS & Skor & NS & Skor & NS & Skor & NS & Skor & NS \\
\hline 1 & Suhu $\left({ }^{\circ} \mathrm{C}\right)$ & 3 & 3 & 9 & 2 & 6 & 3 & 9 & 2 & 6 & 2 & 6 \\
\hline 2 & Kecerahan $(\mathrm{cm})$ & 3 & 3 & 9 & 3 & 9 & 2 & 6 & 2 & 6 & 2 & 6 \\
\hline 3 & Kedalaman $(\mathrm{cm})$ & 3 & 3 & 9 & 3 & 9 & 2 & 6 & 3 & 9 & 2 & 6 \\
\hline 4 & $\mathrm{pH}$ & 2 & 2 & 4 & 2 & 4 & 2 & 4 & 2 & 4 & 2 & 4 \\
\hline 5 & Salinitas (ppt) & 3 & 2 & 6 & 2 & 6 & 2 & 6 & 2 & 6 & 2 & 6 \\
\hline 6 & $\begin{array}{l}\text { Oksigen Terlarut } \\
\text { (DO) (ppm) }\end{array}$ & 2 & 3 & 6 & 2 & 4 & 3 & 6 & 2 & 4 & 3 & 6 \\
\hline 7 & Fosfat (mg/L) & 3 & 3 & 9 & 3 & 9 & 2 & 6 & 3 & 9 & 2 & 6 \\
\hline 8 & Nitrat (mg/L) & 3 & 3 & 9 & 3 & 9 & 2 & 6 & 3 & 9 & 3 & 9 \\
\hline 9 & Pasang surut $(\mathrm{cm})$ & 3 & 2 & 6 & 2 & 6 & 2 & 6 & 3 & 9 & 2 & 6 \\
\hline 10 & Substrat & 2 & 3 & 6 & 3 & 6 & 2 & 4 & 3 & 6 & 2 & 4 \\
\hline & Jumlah & & & 73 & & 68 & & 53 & & 69 & & 59 \\
\hline & Kesesuaian & & & S1 & & S1 & & $\mathbf{S 2}$ & & S1 & & $\mathbf{S 2}$ \\
\hline
\end{tabular}

Keterangan: NS= Nilai Skor, S1= Sesuai, S2= Cukup Sesuai 


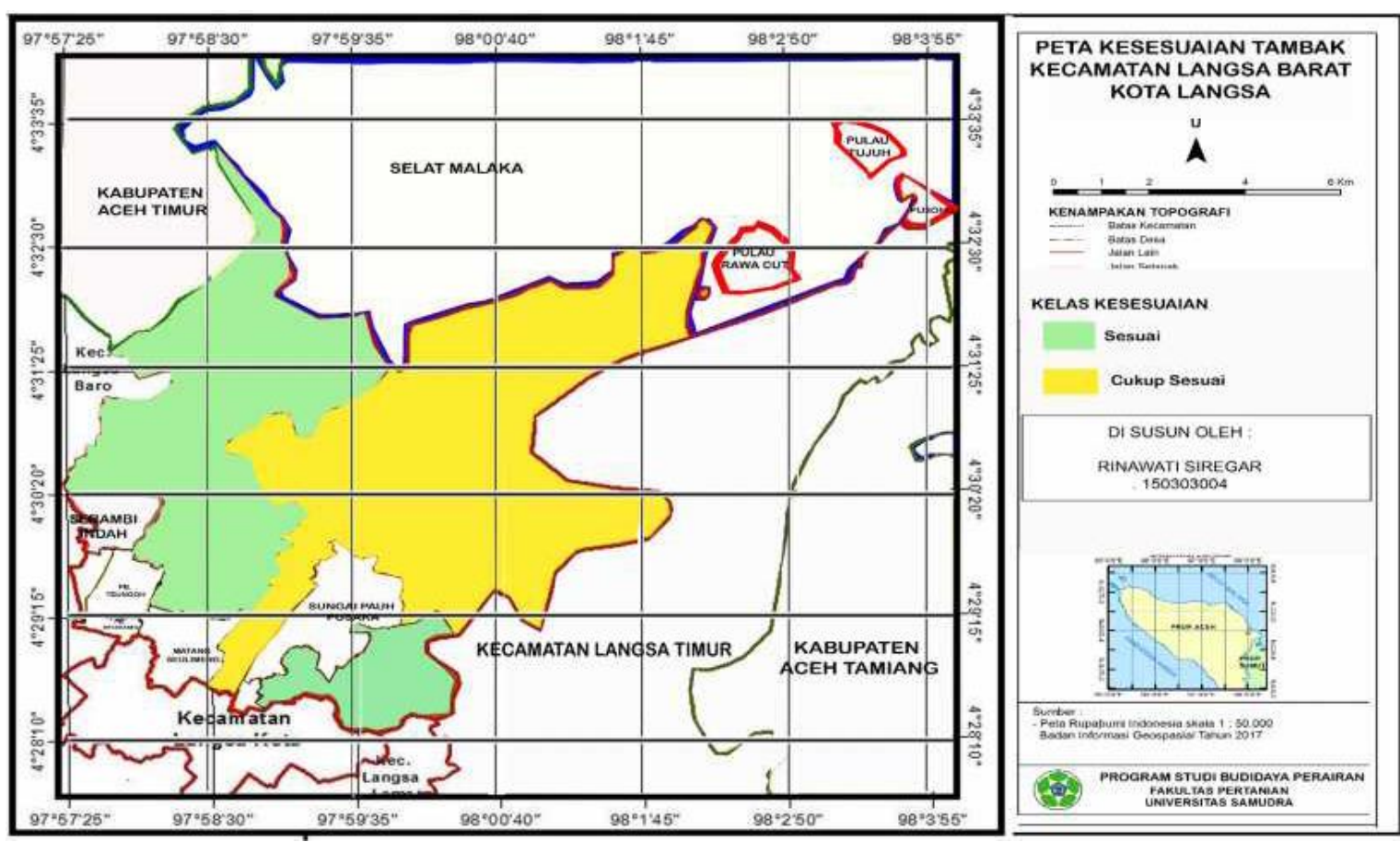

Gambar 11. Peta daerah lokasi lahan tambak berdasarkan kelas kesesuaian untuk budidaya rumput laut (Gracilaria sp.)

\section{KESIMPULAN}

Berdasarkan dari hasil analisis data penelitian dapat disimpulkan bahwa :

1. Stasiun I, satsiun II dan stasiun IV masuk dalam kategori sesuai, sedangkan stasiun III dan stasiun $\mathrm{V}$ dalam kategori cukup sesuai untuk dijadikan sebagai lahan budidaya rumput laut (Gracularia sp.).

2. Daerah Kecamatan Langsa Barat memiliki daya dukung dan karakteristik fisika dan kimia yang baik dengan ratarata kisaran salinitas antara 33-37,4 ppt, pH 7,1-7,5, oksigen terlarut (DO) 4,6-7,5 ppm, suhu $28-33^{\circ} \mathrm{C}$, kecerahan $37-58 \mathrm{~cm}$, kedalaman 56-85 cm, kandungan nitrat 0,45-0,76 ppm, fosfat 0,05-0,14 ppm, dan substat lumpur berpasir dan pasang surut yang optimal untuk dijadikan lahan budidaya rumput laut (Gracilaria sp.).

\section{DAFTAR PUSTAKA}

[1] B. Priono. Budidaya rumput laut dalam upaya peningkatan Industrialisasi perikanan. Media Akuakultur, 8(1), 1-8, 2016
[2] Press, U., \& Indonesia, U. U. R. Study Ekonomi Maritim. Penulis: Akhirman. S. Sos,. MM Cetakan 1, Oktober 2020.

[3] Salim, Z \& Ernawati. Info Komoditi Rumput Laut. Badan Pengkajian dan Pengembangan Kebijakan Perdagangan, Jakarta, 2015

[4] WWF. Budidaya Rumput Laut Gracilaria sp di Tambak. Jakarta: WWF Indonesia, 2014.

[5] C. Yarish, S. Redmond, J.K. Kim. Gracilaria Culture Handbook for New England. Connecticut: Wrack Lines, 2012.

[6] D. Akrim, G. D. Dirawan, \& B. A. Rauf. Perkembangan Budidaya Rumput Laut Dalam Meningkatkan Perekonomian Masyarakat Pesisir Di Indonesia. UNM Environmental Journals, 2(2), 52-56, 2019.

[7] Khalfianur, W., Niati, C. R., \& Harahap, A. Pengaruh gelombang laut terhadap hasil tangkapan nelayan di Kuala 
Langsa. Jurnal Ilmiah Samudra Akuatika, 1(2), 21-25, 2017

[8] Departemen Kelautan dan Perikanan (DKP). Modul Sosialisasi dan Orientasi Penataan Ruang, Laut, Pesisir dan Pulau-Pulau Kecil. Ditjen Pesisir dan Pulau-Pulau Kecil. Direktorat Tata Ruang Laut, Pesisir dan Pulau-Pulau Kecil, Jakarta, 2002

[9] Utoyo et al. Studi Kelayakan Sumber Daya Lahan Budidaya Laut Di Pulau Pulau Sembilan Kabupaten Sinjai SulSel, Teluk Tira Tira, Teluk Kamarudan, Teluk Lawae, Kabupaten Buton Serta Teluk Kalimutu, Kabupaten Muna Sultra. Balitkanta; Maro, 2000

[10] J. Nurdin, J. Supriatna, M. P. Patria, dan A. Budiman. Studi Kesesuaian Budidaya Rumput Laut. Lampung. Universitas Lampung, 2008.

[11] H. Hayati, I. G. N. P. Dirgayusa, \& N. L. P. R. Puspitha. Laju pertumbuhan kerang abalon Haliotis squamata melalui budidaya IMTA (integrated multi trophic aquaculture) di Pantai Geger, Nusa Dua, Kabupaten Badung, Provinsi Bali. Journal of Marine and Aquatic Sciences, 4(2), 253-262, 2018.

[12] S. Mulyani \& E. Indrawati. Budidaya Rumput Laut Potensi Perairan Kabupaten Sinjai Sulawesi Selatan, Pusaka Almaida, Gowa, Sulawesi Selatan, Indonesia, 2021

[13] G. C. Trono. Philipine Seaweeds. National Book Store, Inc. Manila. Pages 174-175, 1998.

[14] N. S. M. Hidayat, N. M. Noor, D. Susanti, S. Saad, Y. Mukai. The Effect of Different $\mathrm{pH}$ and Salinities on Growth Rate and Carrageenan Yield of Gracilaria Manilaensis. Jurnal Teknologi. 77(25):1-5, 2015.
[15] Badruddin dan S. J Boedi. Better Management Pratices. Seri Panduan Perikanan Budidaya Rumput Laut Gracilaria sp. di Tambak. WWF Indonesia, 2014.

[16] Lobban, C.S. and P.J. Harrison. 1997. Seaweed Ecology and Physiology. Cambridge university Press. Cambridge.

[17] H. Effendi. Telaah Kualitas Air. Penerbit Kanisius. 258 hal, 2003.

[18] Sulistijo. Perkembangan Budidaya Rumput Laut di Indonesia. Dalam: Pengenalan Jenis-jenis Rumput Laut Indonesia. Pusat Penelitian dan Pengembangan Oseanologi, Lembaga Ilmu Pengetahuan Indonesia. Jakarta, 1998.

[19] S. N. Sadhori. Budidaya Rumput Laut. Balai Pustaka, Jakarta, 1992.

[20] S. Hutabarat dan S.M. Evans. Pengantar Oseanografi. Universitas Indonesia Press. Jakarta, 2008.

[21] L. I. Guntur \& H. Arami. Aktivitas fotosintesis pada area budidaya rumput laut dan area non budidaya rumput laut di Perairan Pantai Lakeba Kota Baubau. Jurnal Manajemen Sumber Daya Perairan, 2(1), 2016

[22] S. P. Febri, A. Antoni, R. Rasuldi, A. Sinaga, T. F. Haser, M. Syahril \& S. Nazlia. Adaptasi waktu pencahayaan sebagai strategi peningkatan pertumbuhan ikan bawal air tawar (Colossoma macropomum). Acta Aquatica: Aquatic Sciences Journal, 7(2), 68-72, 2020

[23] I. Sukri, A. Arfan \& N. Nasiah. Evaluasi Lahan Tambak untuk Budidaya Rumput Laut Gracilaria sp di Kabupaten Bone. LaGeografia, 19(1), 28-37, 2020. 
[24] A. I. Kanglan. Studi Penentuan Lokasi Untuk Pengembangan Budidaya Laut Berdasarkan Parameter Fisika, Kimia dan Biologi di Teluk Kupang, Nusa Tenggara Timur. Tesis. Universitas Diponegoro. Semarang, 2006.

[25] E. A. Wahyuni, A. Arisandi dan A. Farid. Studi Karakteristik Biologi Rumput Laut Terhadap Ketersediaan Nutrien di Perairan Kecamatan Bluto Sumenep. Universitas Trunojoyo Madura, Sumenep (Dipresentasikan Pada Seminar Nasional Kedaulatan Pangan dan Energi, 2012.

[26] A. Mustafa. Tarunamulia dan J. Sammut. Klasifikasi Kesesuaian Lahan Untuk Budidaya Tambak di Indonesia. Balai Riset Perikanan Budidaya Air Payau. Maros, 2008.

[27] P. A. Sujarwo \& W. P. Fitriyanny. Pengelolaan Budidaya Rumput Laut Berkelanjutan Untuk Masyarakat Pesisir Pulau Panjang Serang, Banten. Jurnal Kebijakan Sosial Ekonomi Kelautan dan Perikanan, 6(2), 123-134, 2016.

[28] W. F. Ma'ruf, R. Ibrahim, E. N. Dewi, E. Susanto, \& U. Amalia. Profil Rumput Laut Caulerpa racemosa dan Gracilaria verrucosa sebagai Edible Food (Caulerpa racemosa and Gracilaria verrucosa Profile as Edible Foods). Saintek Perikanan: Indonesian Journal of Fisheries Science and Technology, 9(1), 68-74, 2013

[29] Utojo, A Mansur, A. M. Pirzan, Tarunamulia, B. Pantjara. Identifikasi Kelayakan Lokasi Lahan Budidaya Laut di Perairan TelukSalleh Kabupaten Dompu NTB. Jurnal Penelitian Perikanan Indonesia, 2004. 